\title{
Study on the Improvement of English Writing Abilities through Online Interactive Activities
}

\author{
From a Constructive Perspective
}

\author{
Chunli Zhang \\ Foreign Language Department \\ Zaozhuang University \\ Zaozhuang, Shandong Province, China
}

\begin{abstract}
The fast development of economy and technology in recent years presents new opportunities as well as challenges for English teaching in China. On one hand, there are higher demands on college English learners' mastery of English. After years of being passive learners and fed with chunks of bitesized knowledge, they are now challenged to become active learners, critical thinkers and communicative writers of English. On the other hand, computer technology is more closely integrated into the language classroom and offers new opportunities for computer-assisted language learning (CALL) activities. In particular, computer-assisted online learning projects prove extremely helpful in the teaching of English writing. Along with these changes, the constructivist learning perspective is highly evaluated currently, which emphasizes learners' active learning and construction of meaning. In the perspective of constructivist learning, teachers should assume more of a facilitators' role and learners take more control over their learning. Hence, it seems that constructivist learning theories will throw hints on the current reform in English teaching. Therefore, the current thesis attempts to explore a new approach to improve students' writing abilities through online interactive writing activities. The thesis starts with the theoretical framework of the study. Then it is followed by the problems existed in current college EFL writing instruction in China and students' expectation to online writing. The latter part of the thesis reports on the experiment about the application of extra curriculum online writing activities, conducted among 36 students from Zaozhuang University. Three hypotheses are put forward. The results of the study show that online writing activities are effective in improving students' writing abilities and teacher acts more of a participant than merely an assistant or coordinator. The thesis concludes with some implications for future studies in this field.
\end{abstract}

Keywords-constructivism; English writing instruction; online writing

\section{INTRODUCTION}

Writing is a difficult skill for native speakers and nonnative speakers alike. It is a complex process, because writers must balance multiple issues such as content, organization, purpose, audience, diction, vocabulary, and mechanics (Rass, 2001). English Writing is especially difficult for Chinese students not only because they are expected to create written products that demonstrate mastery of all of the above elements in a new language but also because they have different cultural and thinking patterns contrasted with the English native speakers.

Writing is a productive skill of the language, which usually comes at the end of the four language skills - reading, listening, speaking, and writing (Brookes and Grundy, 1991). In the four skills, many EFL learners find writing a comparatively weak one partly because, as an output, writing depends on the accumulation and assimilation of input, which is not sufficient, partly because the EFL learners lack the opportunities of authentic communication in the target language. As a result, when they are assigned with writing tasks, they either don't know how to write or have nothing to write about. Teachers also find it difficult when they teach the writing course either because there aren't enough teaching resources to go to or because the sheer marking of the composition poses as a monster of some sort. These problems hinder the effective teaching and learning of writing.

With the focus of education shifted onto students' abilities rather than their knowledge, constructivist learning has emerged as a prominent approach to teaching during this past decade mostly because of its learning-centered approach and its promotion of critical thinking and independent thinking abilities. The field of English language teaching has also evolved accordingly and is increasingly influenced by constructivist learning principles. The constructivist perspective holds that learners are not passive recipients of teacher-imparted knowledge, but rather, learners actively engage in creating meaning for themselves from information around them (Fosnot, 1996). Students in a constructivist classroom are expected to be active participants. The constructivist learning perspective seems to be a hopeful cutting-point to back and steer the present English language pedagogies.

In order to meet the needs of the society, "reform" is the catchword. Language teachers at home are exploring new approaches to writing instruction, such as the process-based approach, the multi-media-assisted approach and the constructivist approach. On one hand, the constructivist learning theories throw lights on possible changes in writing instruction. On the other hand, modern technology, 
especially, computer and the Internet are powerful tools to support the new approaches. Just as Warschauer asserted at LATEFL Conference in 2000 (Warschauer, in press-a), "Technology itself does not determine human behavior, such as how we teach. However, it does create the possibilities for new forms of behavior and of education". Therefore, constructivist learning going hand in hand with modern technology will provide multiple choices for English writing instruction. Some educators have already seized upon computers and the Web as a means of realizing that constructivist learning model in writing, for the computer is an efficient tool to draft, delete, redraft, exchange comments and drafts, and the internet has its connective and communicative resources.

\section{The CURRENT Situation OF THE COLLEGE EFL WRITING INSTRUCTION IN CHINA}

\section{A. Insufficient Information Input}

Most college students have laid a solid foundation on linguistic skills, after studying English for 6 or 7 years and being trained by traditional teaching methods. Most of their compositions show the mastery over grammar, syntax and mechanic. However, little attention is paid to the significant central idea with concrete, substantial, consistent relevant details. As Raimes (1987: 3) has pointed out: "Writing teachers all know how they welcomed the composition that says something to the reader, even if it has some incorrect verb forms". For those teachers, communication in writing is primary and the rest is somewhat peripheral. Grammatical accuracy and rhetorical formulae have little force if the piece of writing is not expressing the writer's ideas clearly and forcefully with an involved imagination. Composing means expressing ideas or conveying meaning

Some students find it difficult to express themselves and hence give up some good, profound thoughts and turn to write simple things within their vocabulary range, some do have little to say about the given topic or feel at a loss as to how to organize an article. The main cause of this situation is insufficient information input, such as the lack of background knowledge and awareness of cultural difference.

For most students, reading is a major way of information input. However, English reading class is far from satisfactory. Under the pressure of the national examinations, many teachers still cling to traditional Grammar-Translation method. In dealing with a passage, they focus on language points. If new words and phrases are explained, grammatical difficulties are ironed out, the reading task is finished. Consequently, what the students gained is just a scattered knowledge about language. The textual pattern of the passage and the information contained in the passage are neglected. While paying attention to the minute points of detail, students have difficulty in storing the information and making use of it because they lack a frame of reference. Since the expressions are learned one after another in isolation, those learnt earlier are not incorporated and are quickly forgotten.
In addition, as the result of the teacher's orientation, most students hold a false belief that learning a foreign language just means learning grammatical rules, remembering words and memorizing structures and patterns. Many EFL students take it for granted that writing is just a process of translating words and filtering meaning from one language to another. More seriously, since pre-college English teaching has covered all the major points of grammar, students' interest in English is killed because in their opinion college English is just the repetition of what they have learned during high school, which is proved by the low attendance in college English classrooms across the country.

It is not suggested that the value of overt grammatical knowledge for the acquisition of proficiency should be denied. "Language learning, besides other things, does involve paying attention to and eventually mastering the formal features of the second language" (Stern, 1992: 143). Raimes (1985) also asserted the importance of grammar for EFL writers but not at the expense of composing practice. However, we must distinguish between grammar as a means and grammar as an end. The objective of College teaching of reading should above all focus on the development of students' communicative competence and crystallize and systemize their knowledge of grammar simultaneously. Many linguists have strongly advocated that College English teaching of reading go beyond sentence level so that students can learn not only the syntactic structure and expressions but also the content encoded in those forms.

As is mentioned in the proceeding section, the presentation and organization of the materials have an impact on students' learning. Therefore, what can be done now is to improve input so that students can absorb large quantities of information, or topic knowledge in such a way that they are available for actual use.

\section{B. Lack of Purpose}

Purpose is the reason for writing. Writers need to consider both audience and purpose in writing because the two elements affect writing significantly, and decision about either the audience or purpose will affect the other. But, according to the data collecting from the questionnaire, $68.3 \%$ students write their compositions for the purpose of finishing the writing tasks assigned by their teachers. Those students never think that they are communicating with the target audience in writing. They seldom think about the reason and purpose of writing before they compose. The student writers, lack of purpose in writing, are likely to find it difficult to be involved in writing. Their writings tend to be largely flat, lifeless, stiff and mechanical, the ideas are somewhat limited or unclear; the attempts to develop context are rare; the papers seem to fail to demonstrate the development of an idea or be lack of persuasion.

The ultimate purpose of writing is to communicate with the particular audience. In order to communicate successfully with the target audience, writers should understand his/her purpose for writing, which makes them write better. Focusing on one's purpose as one begins writing helps him/her know how to choose form, how to focus and 
organize his/her writing, how to cite evidence, how formal or informal the style should be and how much to write (Johnson, 2001). For instance, the purpose in advertising is to sell products. Advertisers seek the audience who are most likely to purchase product. If student writers are asked to write advertisement in this situation, they, first of all, should know their specific purpose and then identify their target audience so that they can capture the attention of audience by their writings. Without the real purpose in writing, the writers' interest cannot be aroused. Zamel (1983) claimed that writing skill can be developed rapidly when students' concern and interest are acknowledged, and when they are encouraged to participate in a community of writing

\section{Neglect of Writing and Writing Class}

Whenever we talk about foreign language teaching, we put the language skills, namely, reading, speaking, listening and writing together. But actually the attention paid by teachers to each of the four skills is distinctly different from one another in China. Reading, surely, has enjoyed the priority in language teaching. Listening and speaking attract much attention. Compared with the other three skills, writing has been overlooked to some extent and less than enough class time is allocated to writing. Students seldom write in English after class, the average writing time after class is no more than 2 hours each week.

Students do not receive adequate training in writing skills, especially at textual level. Teaching writing methods are obsolete and their effects are rather limited. The writing instruction in China generally adheres to the traditional product-based approach. Things often go this way: just a few minutes before the end of a class, the teacher hastily gives a topic and issues the deadline. Students write on the topic after class and at the next meeting of the class turn their compositions in. Responsible teachers go over each student's work sentence by sentence, word by word, revising every spelling error, grammatical mistake, and then return them to students. Less responsible teachers even do not mark the writings at all. They just give a grade or write a date to show they have checked the exercises. When students get their work back, they just give a quick look at it and then put it away and forget about it totally. Without teachers' guidance in writing process, it is no wonder students are afraid of writing and teachers are complaining of low efficiency.

There are many reasons why writing has not received the attention it deserves in classrooms. In the first place, many teachers are uninformed of the theory of writing instruction and seem unaware that writing is a composing process involving planning, drafting and revising stages. Secondly, grading pieces of writing takes time. With large class size and heavy workload, few teachers feel they can afford the extra effort that writing assignments demand. Thirdly, those who have assigned essays have sometimes been so discouraged by their students' underdeveloped writing abilities that they believe to improve the situation just means an insurmountable barrier. Furthermore, they are convinced that they have no class time to devote to writing instruction, because there is simply too much material to cover.
As the above reveals, a large number of students find it difficult when they write either because they don't have anything to write about or because they don't know how to write. Such slogans as "writing is learned by writing", even if partly right, have now been recognized as oversimplifications.

\section{Ineffective Use of Feedback}

In writing instruction, feedback refers to the comments or information learners receive on their writing. As is described in the preceeding part, students do not value the feedback from teachers at all.

Traditionally, it is taken for granted that it is the teacher's responsibility to correct students' errors by providing the correct forms in the margins of the students' exercise books. As in other traditional teaching activities, the students are left in a receptive status in the teaching activity of error correction. If students only receive the results, most students might stop at this stage without exerting more effort to think about their errors. They regard the task of revising as nothing to do with them and slowly become less motivated and completely dependent on the teacher to correct their errors. Moreover, the comments from the teachers are usually about grammatical errors, seldom about content and organizations which also frustrate students. Some teachers even provide only grades or scores without giving any comments, which brings a worse result, for the grades or scores do not feed any suggestions back as to how to write next. Consequently, they don't take the comments seriously due to the fact that they haven't got any benefit from this kind of correction. That is probably why efforts made by teachers to correct students' errors are often not effective and why most students feel they write for their teacher rather than to accomplish something.

Therefore, students should be trained to appreciate feedback and make good use of it to revise their drafts and in the long run to improve their writing ability.

\section{THE PHILOSOPHIES OF INTERNET AND ENGLISH WRITING INSTRUCTION}

Raimes (1983) describes the existing paradigm of teaching English writing via Internet as one which:

- sees language as communication;

- emphasizes real language use;

- recommends a student-centered classroom;

- encourages language acquisition;

- develops humanistic, interpersonal approaches;

- considers the nature of the learner, the learning process and the learning environment.

How, then, does the Internet support this paradigm of the student-centered, communicative and collaborative writing classroom?

In general, to use the Internet is to communicate (Ellsworth, 1994). The main purpose of the Internet is to 
connect people all over the world to share information, experiences, and opinions. Because the Internet is a natural resource (i.e. not a textbook created for the purpose of teaching a language), it contains real language. As students navigate their way around the primarily text-based Internet, they must read and write in English, which helps them acquire the language. Furthermore, various functions of the Internet appeal to different learners' styles. For example, students who are motivated by working independently, or who are visual learners, might benefit more from using the World Wide Web, while students who like to interact and work in collaboration with others would more likely benefit from using MOO.

On the Internet, students and teachers can communicate with individuals and groups, talk in real time, and retrieve information and resources (Warschauer, 1995). The emphasis is on people working together in collaboration rather than in competition with each other. By helping each other, we expand our own realm of knowledge in the process. Internet users store information on Web pages so that it is easily accessible (and downloadable) by others. Participants in MOO can share information and ideas with each other, including lesson plans, activity suggestions and tips on getting started using various Internet functions.

Berge and Collins (1995: 75) further emphasize the collaborative and communicative nature of the Internet:

As an agent for socialization and collaboration, Internet has an even greater potential in education than does the stand-alone, knowledge-server type of computer. The active environment of social learning provided by a computer with access to local, national, and international networks increases interaction and communication among students, their teachers, peers, parents, and other members of the world community. (Berge and Collins, 1995: 75)

In addition to sharing information and resources, there is a general sense that it is important to help others who are new to online environments, rather than judge them negatively for not having prior knowledge of Internet functions and awareness on netiquette (online manners). This supportive environment can be especially helpful in empowering EFL/ESL students, as they will feel comfortable asking questions or taking risks with their language use.

Through computer networks such as the Internet, connecting students and teachers internationally, students gain social skills that increase their empowerment in the classroom. Furthermore, Internet fosters autonomy, equality and learning skills among EFL/ESL learners (Warschauer, Turbee and Roberts, 1994).

Williams (1995) claims that the Internet will have a direct effect on the way teachers teach their students, especially if the teachers' chief goal is to prepare them for life outside the classroom:

The networking culture that will find its way into all schools (if they are to survive) requires participants to be more than just consumers of information and knowledge. They must also become contributors as well... Our kids will become actively involved in research, synthesis and presentation of knowledge rather than passive observers of it. (Williams, 1995: 160)

Furthermore, some researchers describe a shift from a teaching environment to a learning environment in which students are taught through the Internet to become lifelong learners by helping them to locate the resources to continue learning [outside the classroom] (Berge and Collies, 1995).

Overall, the Internet promotes philosophies of shared resources and knowledge, plus active involvement in the learning process. Indeed, this rich resource lends itself naturally to being an effective teaching and learning tool for the student-centered, communicative and collaborative English writing classroom.

\section{APPLICATION OF EXTRACURRICULUM ONLINE INTERACTIVE ACTIVITIES: A PROPOSAL AND THE FIELDWORK EXPERIMENT}

\section{A. A Overall Research Design}

1) Hypotheses of the study: The study is conducted on the assumption that online writing is surely more efficient than traditional way of writing. It aimed to answer the following questions. In which aspects will internet assistance help the students' writing? What role should the teacher play? What pedagogical implications will the internet bring to the traditional writing teaching and study? Thus, three hypotheses in this study are proposed here:

- The assistance of online writing activities can improve students 'writing competence.

- The students 'writing performance can be holistically and equally improved.

- Online writing can ease the burden of the teacher's correction and the teacher acts as an assistant and coordinator.

2) The subjects: The subjects in the experiment are 36 students from Zaozhuang University, 16 females and 20 males, who will soon finish their first year study at university. The writer chooses them as the subjects of the study from two considerations. For one thing, the students are equipped with sufficient grammatical knowledge and vocabulary and their cognitive ability matures with more extensive reading and social interactions. Thus, they are enthusiastic about many social and personal issues. For another, they are computer and internet literate, and the operation of the online writing activities can be run without much technical problems on the parts of the students.

3) Instruments: Three data collection instruments used in the study included a questionnaire for surveying students' attitudes online writing, and the pre- and post-writing test assessing students writing ability.

a) Questionnaire: The questionnaire was delivered to the students at the end of the experiment via E-mail to investigate students' overall attitudes towards online writing. 
b) Writing tests: The students took pre-writing tests before the experiment and post-writing tests at the end of the experiment to measure the improvement of their writing abilities. The two tests are of the same title to ensure the reliability of the results.

4) Procedure: The experiment was conducted from June to September, 2016, which lasted for 10 weeks. It took the form of extracurriculum online writing activities, for it is hardly feasible to be realized in class due to time limitation and technical facilities.

At the beginning, all the students took a pre-writing test to assess their writing competence before the experiment. Then students took various online writing activities after class during the 10-week period. To avoid aimlessness in writing, the students were given one broad topic each week. The students can search related information from the internet and write one composition concerned with this topic. The compositions were required to be sent to the teacher through E-mail. Besides, students can discuss the topic with each other or with the teacher through other online activities, such as BBS or electronic conference. At the end of the experiment, students had a post-writing test with the same title as the pre-writing. The students did not know they would be given the same writing before, so that no one would prepare for it purposefully. A questionnaire survey and an interview were also conducted at the end of the experiment.

\section{B. Various Online activities}

\section{1) Arousing Students 'Motivation with BBS}

BBS is a kind of electronic discussion group. People all over the world whose interests are alike volunteer to organize the electronic discussion group. Some electronic discussion groups are set up by ESL students to offer an opportunity to communicate in English. This bulletin board system provides students with a mechanism and a purpose to share resources in a way that all students could benefit. While a bulletin board is a very stimulating and dynamic means of communication, teachers have to ensure that they keep their students highly motivated throughout. The opportunity to communicate with peers through computers motivates students to pursue, with significant enthusiasm, foreign languages.

The bulletin board system has four main components: a question-and-answer section, a frequently-asked-question section, a section showing authoring tips and tricks and submit URLs. The system has been designed to enable students to share resources through the use of dynamic web pages either as novices trying to find the solutions to problems or as experts providing help and guidance to others in class.

The philosophy behind the system is to enable and encourage the experienced and competent students to provide peer-tutoring and coaching and support for others. At the same time, it encourages those with problems to seek help from peers and to be proactive in the learning process. The bulletin board acts as a dynamic database, which grows as students use the system and provides the forms of learning support usually given by tutors and lecturers.

The two main purposes of this activity are to make students feel at ease writing in English and to give them the chance to express themselves. For these reasons, it does not have the relatively tight structure. Because of the personal nature of some of the comments, the instructor only looks at the articles if students request this or add it to their portfolios.

2) Promoting Collaborative Learning with Homepagemaking

Homepage-making has gained immense popularity in foreign language writing instruction. It allows for the integration of many different facets of computer technology — basic word processing: E-mail and key pals, Internet searches, and Intranet communication project-into the writing processes. And most importantly it provides an opportunity for students to enjoy writing in English with the role of the instructor being not only a facilitator and writing instructor, but also a web technician. Besides that, homepage-making provides an excellent opportunity for students to cooperate among themselves.

Homepage-making sets out to familiarize students with basic typing skills and general computer usage, and goes on to help them understand the Internet with the ultimate goal of using it to create well-designed, well-written and interesting home- pages.

One task for the students in the experiment is to create home-pages about online newspaper reading.

The Internet is a great tool for accessing everyday news from around the world. There are a great many authentic texts, like newspapers, magazine articles and manuals from native English writers on the Internet. Therefore, it is necessary to let students read, interpret and review on-line news. This will give students a chance to become more familiar with everyday life abroad, and help them become more familiar with current events, and build their public writing skills in the target language.

The 36 students worked in groups of six. Each group was responsible to cover one field of news, e.g. economics sports, science, local culture, weather and entertainment, etc.

The website Daily World News (http://www.ohiou.edu/esl/news/daily.htrol) was chosen as the starting point, which is sponsored by Ohio University. This website collects news from all over the world, and it categorizes the news according to their countries. Newspapers from English-speaking countries are listed ahead for EFL teaching and learning purpose.

At the beginning of the experiment, the teacher told students their learning tasks. Then every group discussed in English how to finish their learning tasks cooperatively, reassigning the learning tasks to each group member. Now students could surf freely to view the online news. Every time they should at least browse three kinds of newspapers from different English-speaking countries. This could work as a good basis of comparison for how events were viewed cross-culturally. During the reading process, students could 
discuss grammar problems that they often ran across in their articles, and make new vocabulary lists in their notebooks, summarize and comment on the news in notebooks.

After reading and discussion, students were to create a home-page on the net. The home-pages should include brief summaries or comments on the news in different countries, and students should create hypertext links to the original articles on the net as well as to relevant news reports. Sometimes the teacher visited their homepages, assess the group work and check their performance.

Through the questionnaire to students at the end of the term, it was clear that students liked this activity very much. They all hoped the activity would continue to be set up later. Most of them admitted that the course built on their surfing skills language skills and cultural awareness. Students also gave some useful suggestions to improve it, such as: the teacher should recommend more web sites to students and give more guideline to their home-page making.

\section{3) Creating Interactive Learning Environment with} Electronic Conference

There is now a strong recognition in education of the value of learning environments, which facilitate learners' active participation in the learning process. Computerassisted EFL writing can create an interactive learning environment.

Students make real-time written communications through the Internet, which is called electronic conferencing. Software, such as Real-time Writer, can offer this function. Students can make a written communication, develop their thinking patterns, discuss all kinds of problems and have a collaborative learning with the help of electronic conferencing.

Electronic conferencing is not a "real-time" conference. Electronic conferencing can be classified into two kinds according to the number of participants in communication: the first way is one-to-one communication and the second way is one-to-many communication. Electronic conferencing can also be classified into two types according to communication time: one is synchronous communication and the other is asynchronous communication. Synchronous communication requires learners and teachers to adjust their schedules accordingly to be available and on-line at the same time. This poses several difficulties especially when dealing with people in different time zones; asynchronous communication, on the other hand, provides students with the "capability to learn anywhere and at any time", making it more convenient for learners (Bourne, 1997). Moreover, asynchronous communication allows learners to organize their thoughts so they can produce more detailed and accurate dialogues while at the same time providing them with time to understand what others write. Participants can browse papers and posters, read E-mails, and compose their replies at their leisure. Most participants find no difficulty in setting aside 30 minutes each day for these activities.

The electronic conferencing promotes more equal interaction among participants, dropping barriers of gender, age, social skills and mannerisms, and this is of great benefit to students especially those who are shy, reticent or speechimpaired. Another extraordinary feature of electronic conferencing is that students have enough time to reflect before answering questions and everyone can participate in the activities, avoiding the situation dominated by a few students.

\section{4) Designing Authentic Tasks with E-mail or Pen-pals}

Authentic task is one of the most cited features of a constructivist learning. The best way to learn a language is through interaction with native speakers in real communication situations. Activities on the Internet can provide students with authentic tasks, for example, E-mail and international pen-pals activities.

The authentic activity greatly arouses students' interests in learning because they attach a real meaning to what they do instead of just fulfilling a task assigned by teachers. Authentic tasks should be understood as relating not only to the language in which the learner is engaged but also the social setting which is created in the classroom. In the traditional classroom, it is almost impossible for students to communicate with authentic native English speakers.

The Internet has the potential to create highly authentic learning environments which also enables students to engage in authentic researches on a certain problem. Students can search online databases websites to obtain authentic materials, exchange ideas with peers around the world and even discuss and debate with experts or professionals through the network just as in an international academic forum.

Writing teachers can make use of the authentic writing activities on the Internet to motivate students to write more and better. E-mail discussions and international pen-pals activities offer sufficient opportunities for authentic communications in English.

\section{Findings and Discussion}

\section{1) Questionnaire}

All the 36 students were asked to finish the questionnaire at the end of the experiment. The questionnaire can be divided into 5 parts: learners' attitudes, writing abilities, motivation, autonomy and culture awareness.

The following 5 questions are concerned with students' attitudes towards the online writing activities. "Table I"

TABLE I. THE RESPONSES TO THE QUESTIONS ON LEARNERS' ATTITUDES

\begin{tabular}{|l|l|}
\hline \multicolumn{1}{|c|}{ Statements } & Mean Score \\
\hline 1. Writing online is relaxing and pleasant. & 3.82 \\
\hline 2. I am satisfied with the online writing activities. & 3.48 \\
\hline 3. Writing online gives me a feeling of accomplishment. & 3.26 \\
\hline 4. I have more confidence in writing online. & 3.04 \\
\hline $\begin{array}{l}\text { 5. I would like to continue such online writing activities } \\
\text { after the experiment. }\end{array}$ & 3.51 \\
\hline Overall mean & 3.42 \\
\hline
\end{tabular}

As can be seen in this table, the students had positive attitudes toward online writing. Online writing online gave most students a feeling of accomplishment and confidence. 
The majority of them intended to continue these activities after this experiment was finished. Questions in the following table are related to learner's writing abilities. "Table II"

TABLE II. THE RESPONSES TO THE QUESTIONS ON LEARNERS' WRITING ABILITIES

\begin{tabular}{|l|l|}
\hline \multicolumn{1}{|c|}{ Statements } & Mean Score \\
\hline $\begin{array}{l}\text { 6. Online writing activities have helped me better at } \\
\text { writing in English. }\end{array}$ & 4.03 \\
\hline $\begin{array}{l}\text { 7. I think writing online is a good way to practice EFL } \\
\text { writing. }\end{array}$ & 4.31 \\
\hline $\begin{array}{l}\text { 8. I paid more attention to contents than grammar and } \\
\text { spelling when I wrote online. }\end{array}$ & 3.32 \\
\hline 9. Online writing enlarged my vocabulary. & 3.86 \\
\hline $\begin{array}{l}\text { 10. Overall, online writing is a valuable tool of practicing } \\
\text { EFL writing. }\end{array}$ & 4.16 \\
\hline Overall mean & 3.93 \\
\hline
\end{tabular}

As "Table II" above, the mean score for all students on the relevant five items in the questionnaire was 3.93, much higher than a mean of 3 . Among the individual items, the most positive responses, at a mean of 4.31 were given to Item 7 "I think online writing is a good way to practice EFL writing". Next highest were Items 10, 6, 9 and 8 . It demonstrates most of the students felt that their overall writing ability had improved since they began writing online. Results also show that their writing focused on the communication of meaning rather than the form. Besides, almost every interviewee reported his improvement in English writing and enlargement of English vocabulary since he began writing online. "Table III" shows the results of the questionnaire on learning motivation

TABLE III. THE RESPONSES TO THE QUESTIONS ON MOTIVATION AND INTEREST

\begin{tabular}{|l|l|}
\hline \multicolumn{1}{|c|}{ Statements } & Mean Score \\
\hline $\begin{array}{l}\text { 11. Online writing activities made me more interested in } \\
\text { learning English. }\end{array}$ & 3.92 \\
\hline 12. Online writing activities were interesting. & 4.05 \\
\hline $\begin{array}{l}\text { 13. Online writing activities aroused my enthusiasm of } \\
\text { writing in English. }\end{array}$ & 3.75 \\
\hline $\begin{array}{l}\text { 14. Online writing activities boosted up my initiative in } \\
\text { learning English. }\end{array}$ & 3.64 \\
\hline Overall mean & 3.84 \\
\hline
\end{tabular}

Motivation is always a key issue in the field of education.

It is defined in the terms put forward by Crookes and Schmidt (1991, cited in Peacock, 1997: 145): interest in and enthusiasm for the materials used in class; persistence with the learning task, as indicated by levels of attention or action for an extended duration; and levels of concentration and enjoyment. Most scholars seem to agree that motivation is "one of the key factors that influence the rate and success of second or foreign language (L2) learning. Motivation provides the primary impetus to initiate learning the L2 and later the driving force to sustain the long and often tedious learning process" (Dornyei, 1998: 117).

Furthermore, interest and motivation are closely linked to each other. It is requisite to involve interest when discussing motivation. A Chinese proverb says: interest is the best teacher. When people are interested in something, they learn it quickly and efficiently. The most important thing for our teachers of foreign language to do should be to stimulate the students' interest in the target language. If they are interested in the target language, efficient learning will certainly be achieved.

As it is indicated in the figures, the subjects enjoyed a medium high motivation in online writing activities (the mean score is 3.84). These activities were enormously motivating for students because of the combination of technology, speed of communication and writing for a real audience. When writing just for practice or for a grade, students feel little impetus to do their best work, but when they are writing to an authentic audience, they are careful about their writing because they want to communicate effectively. If students' writings are successfully accepted and understood by other students and friends, they would be greatly inspired and motivated, keeping on using target language as a tool of communication.

Learning is most likely to occur only if students are interested. The responses to the above statements on motivation and interest in the questionnaire suggest that students' interest level was high in the activity and the activity also made students more interested in learning English and EFL writing. The reason behind students' enthusiasm about online writing may be that it makes them feel what they have learned can serve a real purpose in life. Online writing can offer them with their first opportunity to really use the target language outside the classroom and enable students to collaborate and share ideas relevant to their interests and concerns.

The following statements present the result of questionnaire on learners" autonomy. "Table IV"

TABLE IV. THE RESPONSES TO THE QUESTIONS ON LEARNERS' AUTONOMY

\begin{tabular}{|l|l|}
\hline \multicolumn{1}{|c|}{ Statements } & Mean Score \\
\hline $\begin{array}{l}\text { 15. Online writing activities promoted my autonomy on } \\
\text { learning. }\end{array}$ & 3.07 \\
\hline $\begin{array}{l}\text { 16. I am more independent in practicing online writing } \\
\text { than in traditional writing class. }\end{array}$ & 3.82 \\
\hline $\begin{array}{l}\text { 17. I can evaluate what has been acquired in online } \\
\text { writing activities by myself. }\end{array}$ & 2.94 \\
\hline $\begin{array}{l}\text { 18. I feel I become more autonomous in writing since I } \\
\text { am engaged in online writing. }\end{array}$ & 3.75 \\
\hline Overall mean & 3.39 \\
\hline
\end{tabular}

The concept of autonomy, as its name suggests, is "the ability to assume responsibility for one's own affairs" (Sinclair, 1989: 3, cited in You, 2000: 22). "The main characteristic of autonomy as an approach to learning is that students take some significant responsibility for their own learning over and above responding to instructions." (Boud, 1988: 23) Sinclair in another article further asserts, "the development of learner autonomy, at least to some degree, appears to be almost universally accepted as an important, general educational goal" (Sinclair, 1997: 12, cited in You, 2000: 22).

Contemporary language-teaching methodologies make the assumption (either overtly or covertly) that taking an acting, independent attitude to learning--that is, becoming an autonomous learner--is beneficial to learners (Benson, 2001; 
Little, 1991; Wenden, 1998). This assumption is based on humanistic psychology, namely that "the only kind of learning which significantly affects behavior is selfdiscovered, self-appropriated learning" (Rogers, 1991: 276). Good and Brophy (1994: 228) note that "the simplest way to ensure that people value what they are doing is to maximize their free choice and autonomy".

The responses to the 4 statements on learner autonomy in the questionnaire ("Table IV") suggest that features of online writing would promote self-directed learning. Most students could self-evaluate their improvement in online writing activities, and they became more autonomous learners through this. Because the students could take charge or control of their learning without the teacher's obtrusive presence, the on-line environment would be a preferable working environment. In addition, it was hoped that shy students would contribute more actively in this comfortable environment.

The following two statements in "Table V" indicate the results of questionnaire on culture.

TABLE V. The RESPONSES to The QUESTIONS ON CULTURE

\begin{tabular}{|l|l|}
\hline \multicolumn{1}{|c|}{ Statements } & Mean Score \\
\hline $\begin{array}{l}\text { 19. Online writing activities enriched my background } \\
\text { knowledge of foreign culture. }\end{array}$ & 4.12 \\
\hline $\begin{array}{l}\text { 20. Writing online made me more interested in western } \\
\text { culture. }\end{array}$ & 3.92 \\
\hline Overall mean & 4.02 \\
\hline
\end{tabular}

The figures in "Table V" reflect that online writing activities provided students with opportunities to learn about different cultures through web-searching and communication.

It has been proved that culture plays an important role in second language learning. The acquisition of a foreign language should also be the acquisition of its culture, as Brown explains:

It is apparent that culture, as an ingrained set of behaviors and modes of perception, becomes highly important in the learning of a second language. A language is a part of a culture, and a culture is a part of a language; the two are intricately interwoven so that one cannot separate the two without losing the significance of either language or culture. The acquisition of a second language, except for specialized, instrumental acquisition, is also the acquisition of a second culture (Brown, 1993: 165).

Online writing allows students to obtain information worldwide, and to communicate with persons all over the world. So it can provide students with opportunities to discover different cultural settings in a natural way. The students' confidence, awareness and understanding of their own and their correspondents' cultures are improved in the intercultural and cross-curricular activities.

\section{2) Writing Assessment}

Both the pre-writing and the post-writing were held in traditional class settings and the best possible control over test time, coupled with standardized, detailed test protocols across the two tests, was administered to ensure test reliability. Reliability estimates were calculated separately for the pre- $(.09 *)$ and post-writing $\left(.08^{*}\right)$ in terms of Pearson product-moment correlation coefficient. (Li Shaoshan, 2001) The pre-writing reliability is higher than the post-writing reliability by a margin of 0.01 . This difference might be attributable to the fact that the first writings were, on average, shorter, more modest, and generally of "poor" quality, so the raters did not have much to disagree upon; but the second writings were longer and more varied, with some showing obvious improvement, thus inviting more diverse interpretation and judgment on the part of the raters. As a result, the correlation of the ratings between the two raters in the post-writing is not as strong as that in the pre-writing.

The pre-writings were not evaluated until the postwritings were collected. The compositions were scored by two experienced teachers who had been raters of CET Band 4. The assessment of the total scores was determined by content $40 \%$, language use $40 \%$ and organization $20 \%$. The latter two items are calculated on the number of words or mistakes for every 100 words in the students' essays. $20 \%$ in language use goes to grammar and the other $20 \%$ to lexical richness. $10 \%$ in organization goes to conjunctions and the other $10 \%$ coherence. Lexical richness are decided on percentage of words included in Band Four, Band Six and beyond included in the revised version of College English Teaching Syllabus. These factors are not exhaustive, and there are many other factors that could affect the assessment of a piece of writing, but they are the major ones. The detailed information of the writing tests is presented in "Table VI".

TABLE VI. THE DETAILED INFORMATION OF THE WRITING TESTS

\begin{tabular}{|l|l|l|l|l|l|l|}
\hline \multicolumn{2}{|c|}{} & Sd. & T. & Sig. & $\begin{array}{c}\text { Improve } \\
\text { ment }\end{array}$ \\
\hline \multirow{2}{*}{ Total score } & Pretest & 69.2 & 5.98 & -3.62 & 0.001 & $4.9 \%$ \\
\cline { 2 - 5 } & Pretest & 72.1 & 4.68 & & & \\
\hline \multirow{2}{*}{ content } & Pretest & 27.4 & 3.03 & -3.63 & 0.001 & $9.1 \%$ \\
\cline { 2 - 5 } & Pretest & 29.5 & 2.69 & & & \\
\hline \multirow{2}{*}{$\begin{array}{l}\text { Language } \\
\text { use } \\
\text { organization }\end{array}$} & Pretest & 27.8 & 2.25 & -2.05 & 0.047 & $2.8 \%$ \\
\cline { 2 - 5 } & Pretest & 28.5 & 2.84 & -0.21 & 0.829 & $0.7 \%$ \\
\cline { 2 - 4 } & Pretest & 14.0 & 1.53 & & & \\
\cline { 2 - 4 } & Pretest & 14.1 & 1.70 & & & \\
\hline
\end{tabular}

From the above table, the total score is improved by $4.9 \%$, within which content tops the three aspects with the improvement of $9.1 \%$, with language use following it, increased by $2.8 \%$. But there is no significant improvement in organization. From the data, we can see that the students' writing performance can be holistically improved but cannot be equally improved.

Just as Vygotsky (1978) puts it "human learning presupposes a specific social nature." An essential feature of learning is that it awakens a variety of internal developmental processes that are able to operate only when the child is in the action of interacting with people in his environment and in cooperation with his peers. Therefore, when it comes to language learning, the authenticity of the environment and the affinity between its participants are essential elements to make the learner feel part of this environment. Online writing offered such an environment to which most participants referred to as "a stage for our free discussion and writing" and "a new area for learning 
English". Students' motivation and autonomy were highly inspired, thus their writing abilities were improved by $4.9 \%$, as showed in the above table.

Compared with content, language use was not improved so significantly, only $2.8 \%$. The reason may be that the online writing has no functions for checking spelling and grammar mistakes. Without the automatic correction, the students were not reminded of their mistakes and thus their awareness was not greatly developed.

Writing, like speaking, is another kind of output. Unlike reading and listening, which to some extent are a kind of stimulus-response, with linguistic units and sound signals as the sources of stimulus, writing and speaking are the production of thought in the form of words. Without the above mentioned stimulating input in reading and listening, the words and expressions should be internalized before they can be put out spontaneously and this is particularly true in writing where, without the receiver's presence, the communication depends solely on language used. Furthermore, as EFL writers, they have great difficulties in using the target language if they are not in the environment where the target language is often used in authentic interaction. So it is understandable for language use to be moderately improved compared with content within such a short period of time.

The reasons that there is no significant difference in organization between the pre-writing and post-writing may come as follows. First, the Chinese students are weak in organization in English writing, discourse in particular. The writing instruction in Chinese FLT has been focusing on word and sentence level rather than on discourse level. Grammar is overemphasized whereas text structure is neglected. Thus the students pay attention to sentence structure and spelling rather than to the cohesive ties among the sentences. The same problem occurred in peer revision during online writing. Nearly each grammar mistake was identified and corrected. With regard to organization and structure, the revisers just found there was no way to correct or improve. The second reason is that the students' awareness of organization and cohesion was not stressed in the study. In the pre- and post-writing an individual score was given to the two aspects, but in teacher evaluation and peer revision, no importance was attached to them except an impressive total score. Even the students realize the problem, they just could not figure out how to revise.

Other studies in this area focused on the overall improvement of writing performance. The more detailed aspects such as content and organization were not given special attention. The writer employs a different approach to explore not only the overall performance, but also the individual aspects.

\section{CONCLUSIONS AND IMPLICATIONS}

The study was administered to answer the three questions proposed in "Hypothesis of the Study". The underlying theories, which are Constructivism, Second Language Acquisition and Input and Output Hypothesis, are the guidelines in the conduction of the study. Pretest and protest constituted a comparison and contrast, making the study doubly effective. Each of the questions was given individual consideration in the whole process. Answers were produced either by qualitative or quantitative methods.

\section{A. Major Findings}

The extracurriculum Internet-assisted interactive writing activities as a CMC (computer mediated communication) are a virtual extension of the FFC (face to face communication) not only between the teacher and students but among the students themselves as well. In fact there was no essential distinction in content between the classroom and extracurriculum activities. The major differences were in the role of the teacher and students. In the classroom activities, the students were asked to discuss questions besides the teacher's instruction which was based on the overall arrangement and the students' problems showed online in the past week. So it was content-based, with the teacher mostly controlling and organizing. The students are given some room but very limited due to the insufficient class time and reserved nature of Chinese students. While in the extracurriculum activities, the students gained a lot of freedom and they can communicate with whomever he felt like and about whatever topics interesting them. Apart from chatting, there are various activities such as homepagemaking and BBS. Therefore it is student-centered and taskoriented, and when it comes to writing, these activities function equally and even better than the FFC, rather than just "complemented" it.

Through the 10-week online practice of formal writing and informal interactions, the students' writing ability demonstrated comprehensive improvement. A new finding is that different aspects did not equally advance, with content improved the most and organization the least, and language use in between. More new ideas are activated through online interaction and reading, which attributes to the richness of content. This change is revolutionary if we consider the fact that the compositions of most Chinese students lack in content (Kong \& Cheng, 2002). Discourse has been the weakness of the Chinese students in English writing. For one thing, there are some differences between the Chinese and English discourse, for another, most teachers neglect the introduction and analysis of it. Regarding this, the students as a whole have no awareness in this aspect. This holds true to the subjects in the study.

A very significant finding is the teacher's roles in Internet-assisted practice. The related published literature is very few and most of which is limited to the study in the classroom. In fact, even in extracurriculum CALL, the teacher's role needs to be more potent than has been acknowledged so far. The teacher is far from "an assistant and coordinator", as stated in the Hypothesis 3 in Chapter 4. $\mathrm{He} / \mathrm{she}$ is first a most frequent participant and administer apart from the often referred ones like a facilitator, supervisor and evaluator. The teacher as a participant serves as a model for the students and his/her output can also act as examples of good English. 
In the on-line environment, language teachers need to be active in responding to the students' questions and maintaining a kind of order. In essence, language teachers must take the plunge and approach the Internet as a learning experience themselves. The more enthusiastic and more knowledgeable the language teachers are, the more successfully they can complement the Internet in the language classroom. This does not mean that the teachers should do the same as in-class CALL instruction to ensure that the time that is spent on on-line work is not wasted, or to prevent students from viewing material which is not appropriate for them and finally to maintain their attention and guide them on the Web so that they become focused on the assigned task. All this is in fact very unnecessary for the extracurriculum one as in the present study. The teacher's guidance here is overall and macro, not in detail and micro.

In technologically rich environment, there is even a role reversal where teachers utilize student knowledge and expertise. This is also the case in the online writing, and the teacher-student relationship has been shifted to one of cooperative learning and peer tutoring.

There is no answer as to what extent the teacher should involve in the extracurriculum online study, but one thing is certain, that is, lack of teacher's involvement will lead to loss of control and, on the other hand, too much will contribute to the teacher's dominance, the students' reliance and their loss of ownership.

Although the perspectives described originate from one institution and its specific institutional context, the emerging issues may have global implications. The common moves described above and the student views indicate how students had used the technology to extend and enrich their learning experience within the classroom context. Indeed every pedagogic endeavors has its problems and pitfalls as, of course, it has potential and possibilities. For this online writing experiment, the potentials included rich interactions supported by two complementary modes (face-to-face and Web-based) and a keen sense of responsibility, while the pitfall was in the kind of workload-related stress whole experience had created. Indeed the workload was felt to be overwhelming by the teacher as well. Yet for the teacher, there was tremendous satisfaction when L2 students, who had never heard the word "genre" or "semiotic code" were questioning how the stages in a genre were arrived at and explaining semiotic terms to each other-using only English. It was also fascinating to go back to the classroom data and see the social processes within which students co-constructed and contextualized their Web-based classroom communities and as a teacher reflect upon the quality of his own contribution in this socializing process

However, this is just a 10 -week small-scale study. If the study could be prolonged and the number of subjects could be increased, the qualitative and quantitative results would be more scientific. As a small-scale preliminary study, it might throw lights on further studies in computer-assisted writing.

\section{B. Implications}

This study on Internet-assisted language learning has great implications for the future EFL study. The most significant influence on the evolution of education will not be the technical development of more powerful devices, but the professional development of wise designers, teachers, and learners. Firstly, both teachers and students need to be trained how to use communication technologies effectively and appropriately. To achieve this, Warschauers' electronic literary approach (1997) puts forward a useful framework which integrates electronic literacy into the language learning classroom. This framework is divided into three key areas: communication, construction and research. Communication refers to the skills of contacting individuals and groups on the net and participating in collaborative projects on-line. Construction covers the creation, maintenance and marketing of web-sites, and finally, research looks at the learner's ability to find information on the web and to consequently evaluate its value and determine the authority of its author.

The transformation from a traditional to an informationbased society is occurring rapidly throughout the world, causing everyone to be involved in one way or another, whether by individual choice or not. In this sense everyone is a part of, and involved in, the information revolution. We must discard the notion that teachers and educators are the only people making an effort to change EFL pedagogy or that computers are the only element causing this change. This study has aimed to illustrate what changes are taking place in the area of language learning, focusing on independent Chinese EFL learners, as the Internet becomes a more integral part of our lives. The study explores students' writing improvement in this new context-their learning processes, learning goals, attitudes toward learning, and their relationship with other learners and teachers are undergoing change, and the teacher roles and responsibilities will accordingly experience some revolutions.

\section{CONCLUSION}

This study was meant to be a first step in investigating Internet-based language learning. 36 subjects and 10 weeks do not provide enough data to make the results generalizable. However, the main objective of the study was to gain valuable insights and understanding toward this learning style (Internet-based language learning). In this sense, this study has contributed to the knowledge base of this new form of learning and it is believed that some of the conclusions in this study are valuable for those who wish to investigate Internet-based language learning further.

\section{REFERENCES}

[1] Berge, Z. \& Collins, M. (1995). Computer-mediated Communication and the Online Classroom in Distance Learning. Cresskill, NJ: Hampton Press.

[2] Coe, R. M. (1987). An Apology for Form: or, Who Took the Form out of Process? College English, 49, 123-28.

[3] Connor, U. (1996). Contrastive Rhetoric: Cross-cultural Aspect of Second Language Writing Cambridge University Press. 
[4] Cook, G. \& Seidlhofer,B. (1995). Principles \& Practice in Applied Linguistics. Oxford: Oxford University Press.

[5] Jonassen, D., Peck, K., \& Wilson, B. (1999). Learning with Technology: A Constructivist Perspective. Canada: Prentice Hall.

[6] Kong \& Cheng (2002). English Teaching Reform and the Application of CAI. Computerized Foreign Language Teaching. No. 83.

[7] Krashen, S. (1982). Principles and Practice in Second Language Acquisition. Oxford: Pergamon.

[8] Krashen, S. (1985). The Input Hypothesis: Issues and Implications. London: Longman. 